\title{
Characterization of the Thermo-Microstructural Analysis of Raffia Palm Fibers Proposed for Roofing Sheet Production
}

\author{
R. S. Odera ${ }^{1}$, O. D. Onukwuli ${ }^{1}$, C. U. Atuanya ${ }^{2}$ \\ ${ }^{1}$ Department of Chemical Engineering, Nnamdi Azikiwe University, Awka, Nigeria \\ ${ }^{2}$ Department of Metallurgical and Materials Engineering, Nnamdi Azikiwe University, Awka, Nigeria \\ Email: stonechemicals2015@gmail.com
}

Received 23 May 2015; accepted 20 July 2015; published 23 July 2015

Copyright (C) 2015 by authors and Scientific Research Publishing Inc.

This work is licensed under the Creative Commons Attribution International License (CC BY).

http://creativecommons.org/licenses/by/4.0/

(c) (i) Open Access

\begin{abstract}
Raffia fibres are made from fibrous branches and leaves of Raffia palm. The membrane on the underside of each individual frond leaf is taken off to create a long thin fiber. They are usually waste materials which cause a great environmental degradation. The characterization of Raffia palm fibers/particles was investigated through X-ray diffractometer (XRD), thermogravimetric analysis (TGA/DTA), Fourier transform infrared spectrometry (FTIR), Scanning electron mi croscope with energy dispersive spectrometer (SEM/EDS) and Atomic force microscope (AFM). The various results obtained are equivalent to those of other agro-waste materials generally used in roofing sheets composites production. Hence, this work shows that Raffia palm fibers/particles can be a useful material for cement mortar composites production which can be used for production of roofing sheets.
\end{abstract}

\section{Keywords}

Raffia Palm Fibers, Thermogravimetric Analysis, Atomic Force Microscope (AFM), X-Ray Diffractometer (XRD)

\section{Introduction}

Academic institutions and fiber cement producers have been engaged for the past 25 years in intensive research to find substitutes and to develop processes for the industrial production of asbestos free fiber materials for ${ }^{*}$ Corresponding author.

How to cite this paper: Odera, R.S., Onukwuli, O.D. and Atuanya, C.U. (2015) Characterization of the Thermo-Microstructural Analysis of Raffia Palm Fibers Proposed for Roofing Sheet Production. Journal of Minerals and Materials Characterization and Engineering, 3, 335-343. http://dx.doi.org/10.4236/immce.2015.34036 
roofing applications [1]. The need for economical, sustainable, safe, and secure shelter is an inherent global problem and numerous challenges remain in order to produce environmentally friendly construction products which are structurally safe and durable. The use of natural fibers with enhanced mechanical performance, as reinforcement in a cement based matrix, has shown to be a promising opportunity [2]-[4].

Due to their low cost and low weight, natural fiber composites have found applications in various uses, such as housing units, roofing, wood substitutes, etc. [5] [6]. For developing countries to benefit from these composites, it is necessary to resolve several issues relating to their cost and ease of production. It is argued that natural fiber composites will succeed more in the markets if they are proven to cost less than conventional composites for equal functions [7]. However, the cost of producing composites has to be low enough just to let the industry begin in developing countries. Therefore, attempts to introduce composites in these countries will benefit from use of cheap raw materials and simple processing techniques. The immediate solution for low cost materials is to focus on locally available, cheap and abundant natural fibres and plastics. For instance, in the Province of Bohol in the Philippines, Kuba of Democratic Republic of the Congo, Nso of Cameroon, the Igbo and Ibibio/ Annang of south-Eastern, the Urhobo and Ijaw people of Niger delta Nigeria and the Yoruba of South-Western Nigeria, among several other West African ethnic nations, one of the abundant sources of strong natural fibres is Raffia palms (Raphia) [8]. This is a source of one of the most underused and least studied fibres [9].

The Raffia palms (Raphia) are genus of about twenty species of palms native to tropical regions of Africa, and especially Madagascar, with one species ( $R$. taedigera) also occurring in Central and South America [10]. They grow up to $16 \mathrm{~m}(52.5 \mathrm{ft})$ tall and are remarkable for their compound pinnate leaves, the longest in the plant kingdom; leaves of $R$. regalis up to $25 \mathrm{~m}(82.38 \mathrm{ft})$ long and $3 \mathrm{~m}(9.84 \mathrm{ft})$ wide are known [11]. The plants are either monocarpic, flowering once and then dying after the seeds are mature, or hapaxanthic, with individual stems dying after fruiting but the root system remaining alive and sending up new stems [11]. Raffia fibres have many uses, especially in the area of textiles and in construction. In their local environments, they are used for ropes, sticks and supporting beams, and various roof coverings are made out of its fibrous branches and leaves. The membrane on the underside of each individual frond leaf is taken off to create a long thin fiber which can be dyed and woven as a textile into products ranging from hats to shoes to decorative mats [11]. Plain raffia fibres are exported and used as garden ties or as a "natural" string in many countries. Especially when one wishes to graft trees, raffia is used to hold plant parts together as this natural rope has many benefits for this purpose [10]. Work on the physicochemical characterization of exudates from Raffia palm (raphia hookeri) was carried out by Akpabio et al. [10] whose research concentrated on the nutrients values of the raffia palm fibers to serve as a feed for livestock. Based on the forgoing this research reported for the first time the thermo-micro structural analysis of Raffia palm fibers to be use for roofing sheets production.

\section{Method}

In this research the Raffia palm used was fibers and particulate. The Raffia palm fibers were obtained from Awka Nigeria (Figure 1), they were freed of dirt and organic matter.

The Raffia fibers were cut into the required length and thickness in line with that in the author's previous work [9]. Some of the Raffia palm fibers were packed in the air tight graphite crucible placed inside electric control furnace and fired at a temperature of $1200^{\circ} \mathrm{C}$ for 5 hours to obtain a black color ash which is the Raffia palm fiber ash (RPFA) which was used in the research. The particle size distributions of the Raffia palm fiber ash (RPFAp) were determined using American Foundry Society (AFS) specifications [10]. The X-ray diffraction

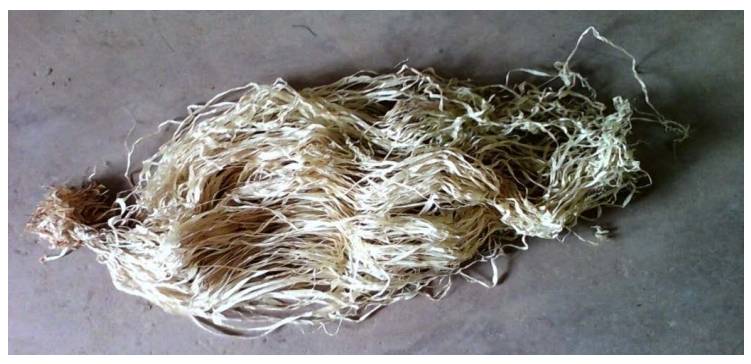

Figure 1. Raffia palm fibers. 
patterns of the RPF and RPFAp samples were determine by X-ray diffraction analysis which was carried out with a Siemens D-500 diffractometer using Co-Kc radiation $(\mathrm{Kc}=1.79026 \mathrm{~A})$. The microscopic studies were determined by JEOL JSM840A scanning electron microscope (SEM) complemented by EDS and Atomic Force Microscopy (AFM). All the analyses were carryout at the University of the Witwatersrand, Johannesburg, South Africa. Fourier transform infrared spectrometry (FTIR) was carried out on RPF and RPFAp as well. IR spectra were recorded using Perkin Elmer spectrum 100 FT-IR spectrometer in the frequency range $4000-300 \mathrm{~cm}^{-1}$, operating in ATR (attenuated total reflectance) mode. Thermal decomposition analyses of RPF and RPFAp were investigated in terms of global mass loss by using a DTA/TGA Instrument TGA Q50 thermogravimetric analyzer. The Differential scanning calorimetry (DSC) analysis was carried out using a TA Instruments DSC Q 10. The samples were scanned at a heating rate $20^{\circ} \mathrm{C} / \mathrm{min}$, using a nitrogen air 143 flow of $50 \mathrm{~mL} / \mathrm{min}$.

\section{Results and Discussion}

The density of the RPF and RPFAp were found to be $0.3 \mathrm{~g} / \mathrm{cm}^{3}$ and $0.21 \mathrm{~g} / \mathrm{cm}^{3}$ respectively. These values are lower than the density of Portland cement $\left(1.25 \mathrm{~g} / \mathrm{cm}^{3}\right)$ and silica sand $\left(2.4 \mathrm{~g} / \mathrm{cm}^{3}\right)$ that are used in the production of mortar, this means that addition of Raffia palm fibers in mortar will lead to the production of light weight building materials [4]. The XRD pattern of the RPF and RPFAp is shown in Figure 2. It can be clearly observed that the diffraction peaks appear in the pattern corresponding to phase with good crystalline nature. The higher diffraction peaks of the RPF and RPFAp are $30^{\circ} \mathrm{C}$ and $35.7^{\circ} \mathrm{C}$ cor responding to $\mathrm{SiO}_{2}$ and $\mathrm{C}$ phases. The XRD pattern of RPFp has similar features to that of RPF but with more diffraction peaks and Carbon phase, which may be attributed to the carbonization of the RPFAp. The grain sizes of the fibres and particles are found to be about $156.7 \mathrm{~nm}$ and $89.5 \mathrm{~nm}$ for RPF and RPFAp respectively, Peak broadening depends principally on the crystal lite of the crystallite size, the crystallite size and crystallinity index of the RPFAp (25.6\%) is higher than the RPF (22.3\%).

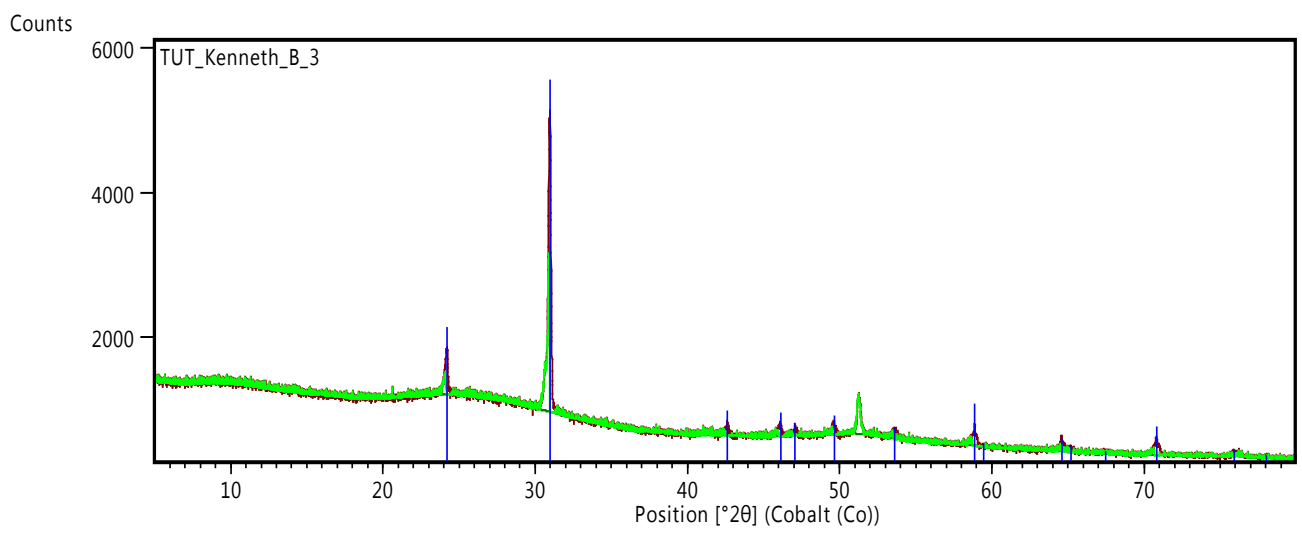

(a)

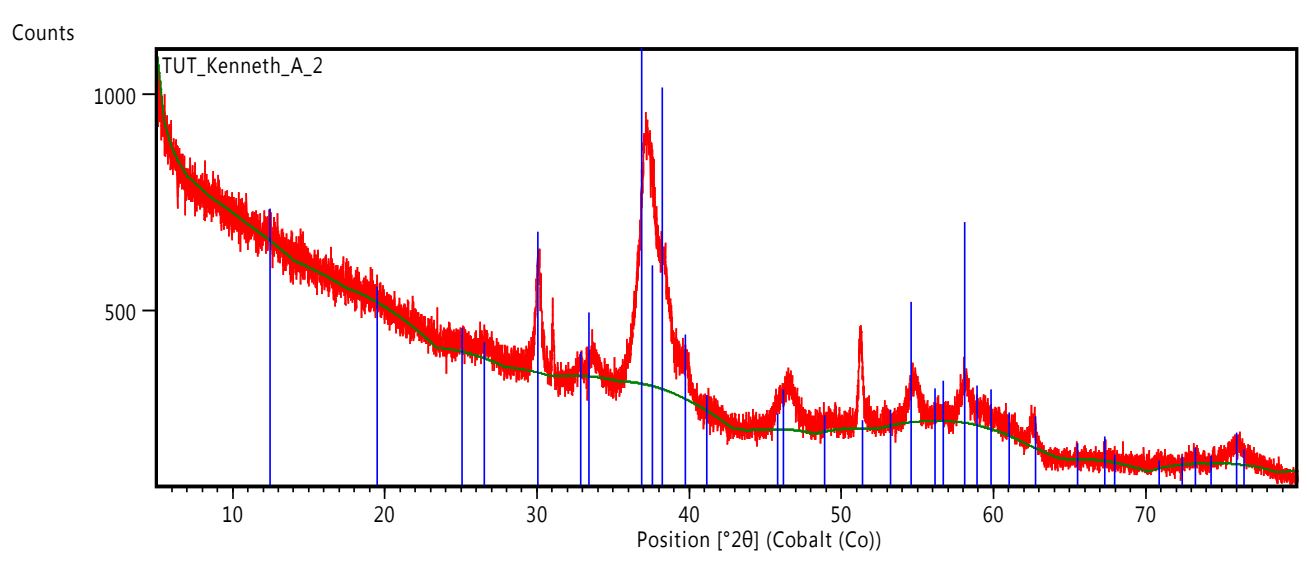

(b)

Figure 2. (a) XRD of RPF; (b) XRD of RPFAp. 
The removal of the hemicelluloses and lignin in the RPFAp which are amorphous components of the fiber contributes to the increase of the crystallinity index. XRD analysis of RPF and RPFAp showed a diffraction peak at $20^{\circ} \mathrm{C}\{001\}$, which is designated to graphitic carbon. Moreover, peak at $43^{\circ} \mathrm{C}$ is also seen in the Figure 2 that is known to be associated with carbon $\{111\}$. A small peak present at $78^{\circ}$ of XRD of Raffia palm fiber depicts the presence of the Silica. However, the graphitic peaks are not very prominent in RPF samples. With the presence of hard phases of $\mathrm{SiO}_{2}, \mathrm{C}$, in Raffia palm fiber means, it has similar composition with other biomass currently used in building construction [5].

The morphology of the Raffia palm fibers was investigated using SEM. Figure 3 shows the SEM image of the RPF and RPFAp. The spherical shaped particles distributions are visible through the SEM analysis of the RPFAp. From the SEM analysis of the RPF it can be observed that the fibers are not roundish but longitudinal in shapes and continue form which confirms that the fibres can be used for continuous fiber fabrication (Figure 3(a)). The fiber/particles surface morphology plays a vital role in case of composite materials. External features of particles such as contours, defects, damage and surface layer were not seen in the SEM. Energy dispersive spectrometer (EDS) used for the microanalysis to quantify the elements in the Raffia palm fibers show that the RPFAp has higher carbon(C) peak than the RPF. This is attributed to the carbonization of the Raffia palm fibers. The RPF has elements such as $\mathrm{C}, \mathrm{H}, \mathrm{O}$ which are major peaks that confirm the organic nature of the RPF.

The Surface topography was studies with atomic force microscope (AFM) measurements to determine the grain
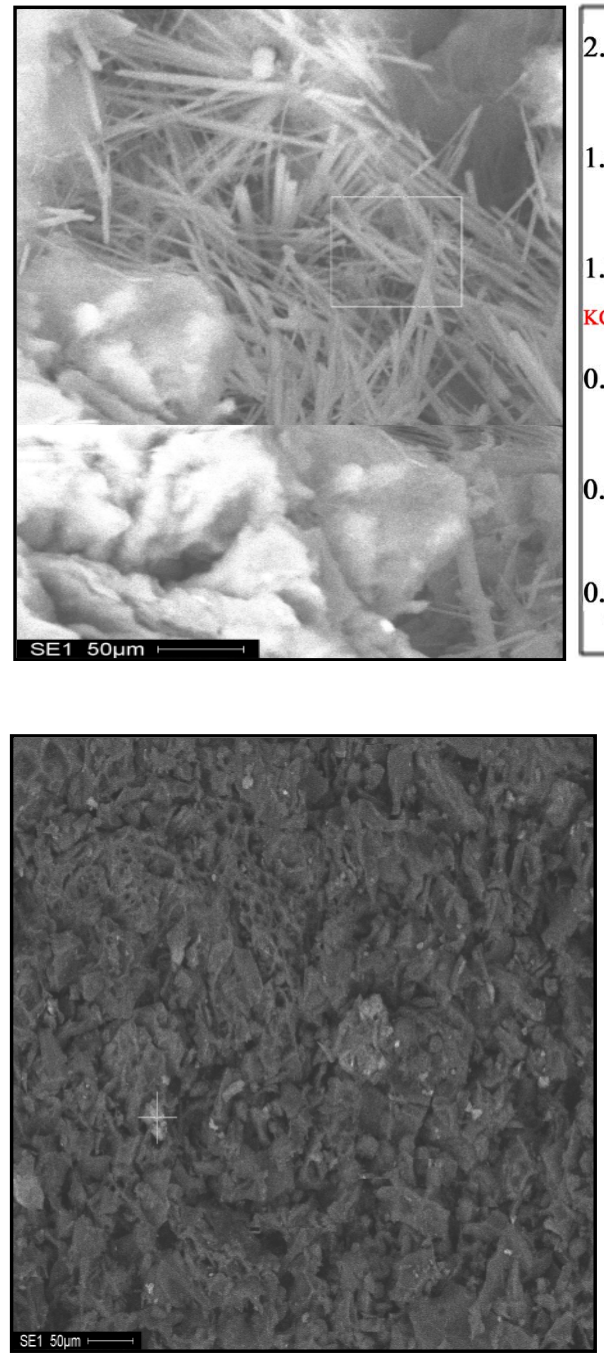

Figure 3. (a) SEM/EDS of Raffia palm fibers; (b) SEM/EDS of Raffia palm fibers ash particle.

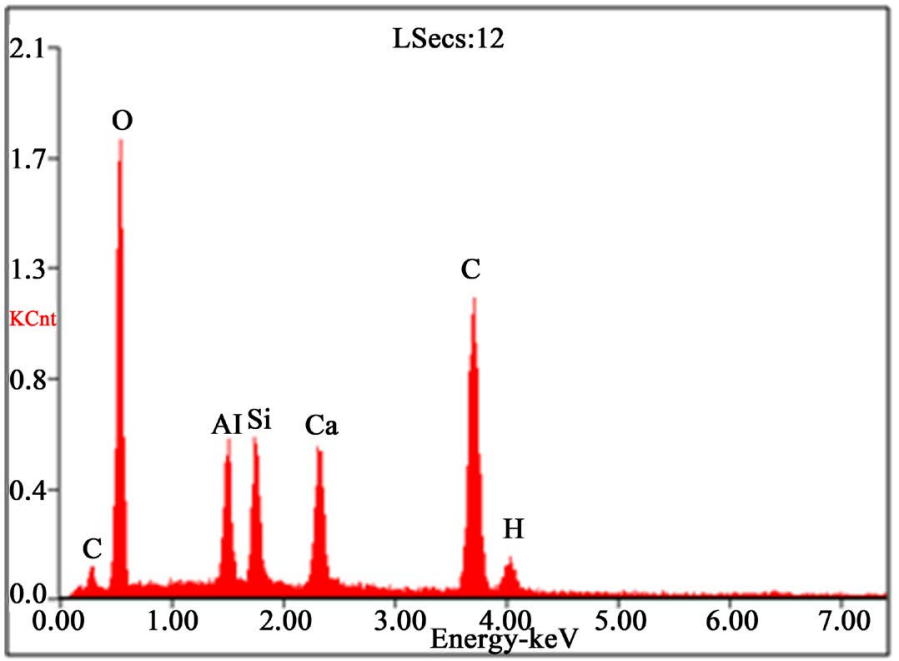

(a)

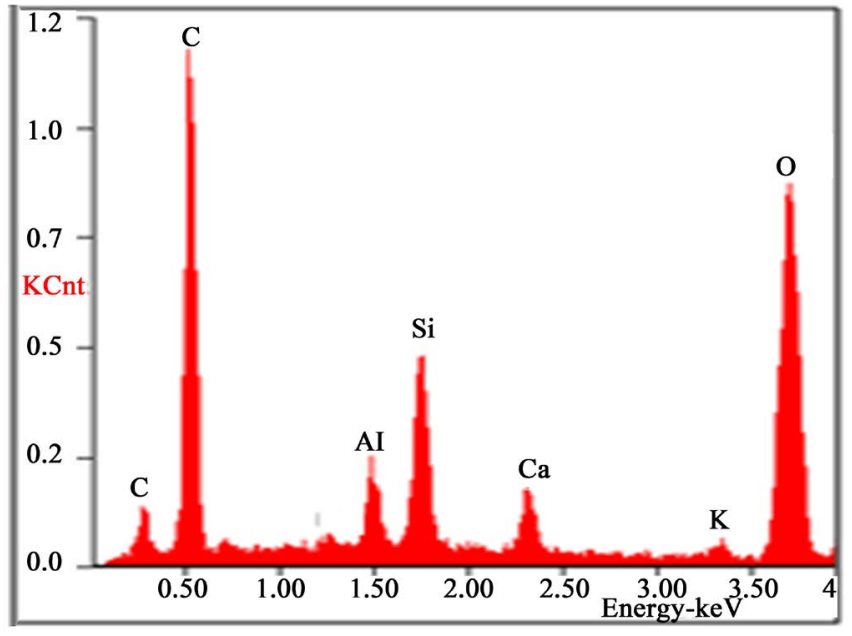

(b) 
size dimensions of the RPF and RPFAp. Figure 4 shows the 2D and 3-D AFM images of the RPF and RPFAp. In AFM images, uniform crystallites with small grains were found affirming the morphological result obtained from scanning electron micrograph RPFAp. Figure 4(a) reveals the longitudinal nature of the Raffia palm fibers which is more visible in the 2D-AFM pattern. In Figure 4(b), growth of spherical crystallites cover the entire surface, thereby giving it a uniform appearance and finer grained texture.

FT-IR spectroscopy is an effective tool for studying the physico-chemical and conformational properties. Figure 5 shows the FTIR spectra of RPF and RPFAp. There broad peaks ranges from $324.04-3047.53 \mathrm{~cm}^{-1}$ and $324.04-3950.22 \mathrm{~cm}^{-1}$ for RPF and RPFAp respectively. The peak broad at $3047.53 \mathrm{~cm}^{-1}$ is assigned to the hydroxyl groups (-OH) of RPF. The peak at $2600.04-2908.65 \mathrm{~cm}^{-1}$ related to $\mathrm{C}-\mathrm{H}$ stretching and $1782.23 \mathrm{~cm}^{-1}$ is attributed to $\mathrm{C}^{1 / 4} \mathrm{O}$ stretching of carboxyl groups from hemicellulose. The small peak presence at $1581.63 \mathrm{~cm}^{-1}$ is indicated as conjugated $\mathrm{C}-\mathrm{O}$ group from aromatic skeletal in lignin. The peak at $1442.75 \mathrm{~cm}^{-1}$ is correspond-
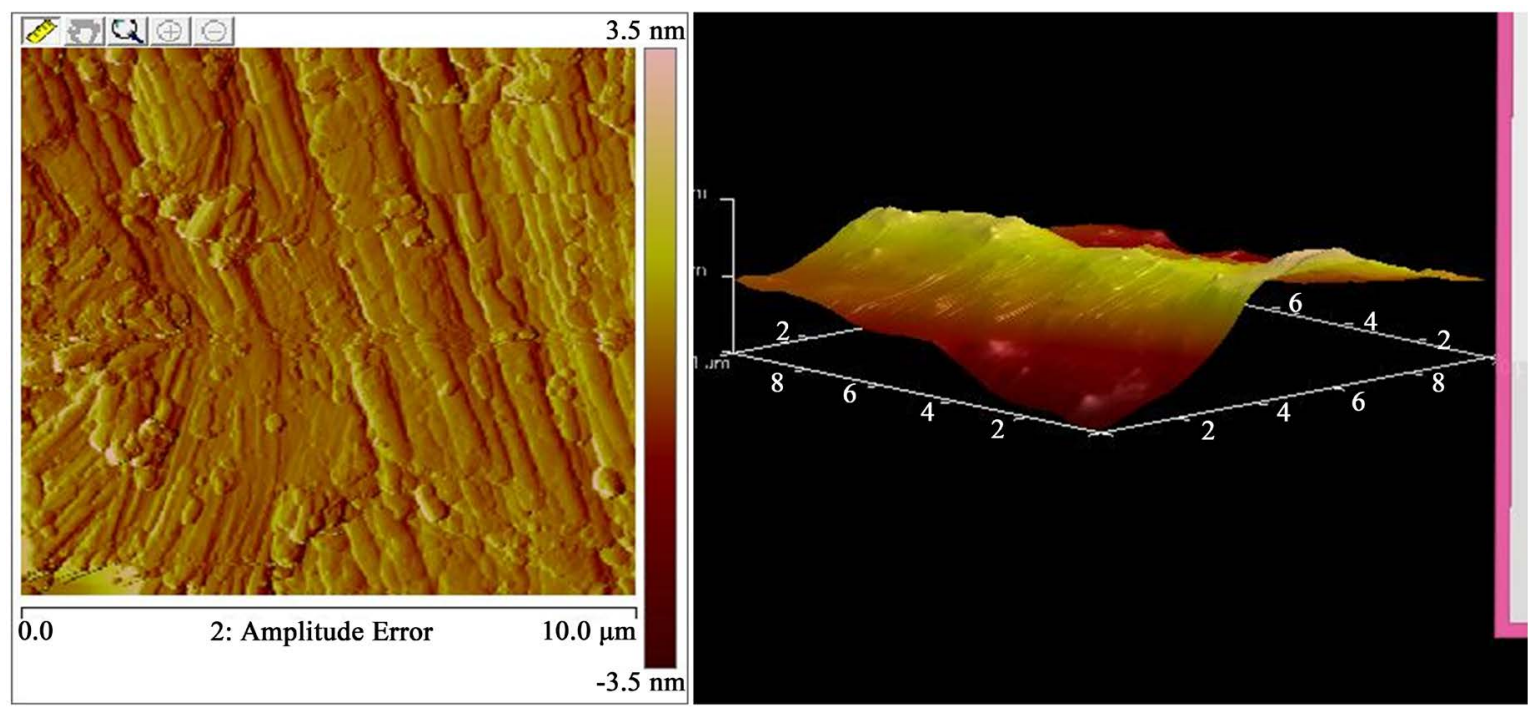

(a)
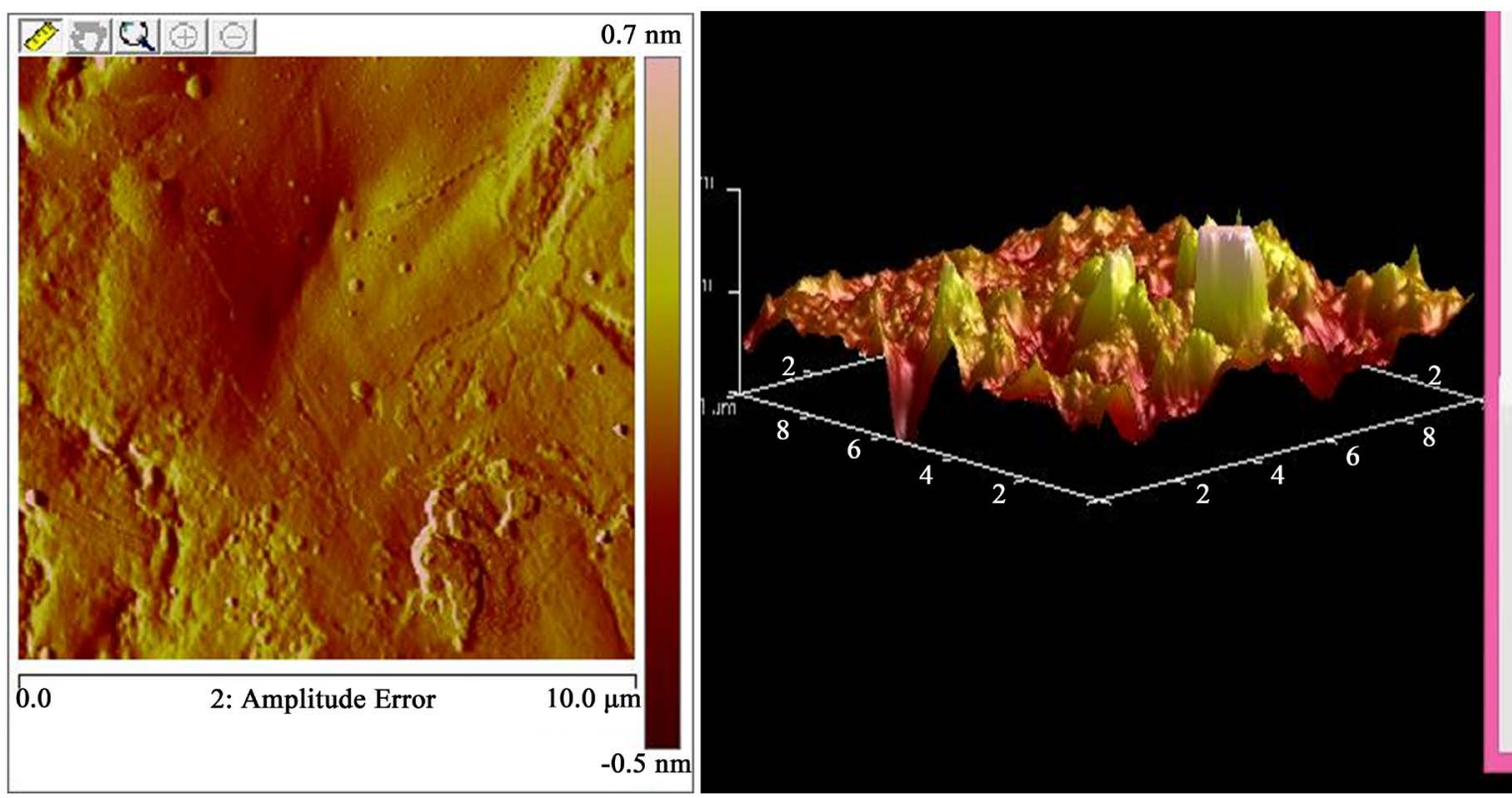

(b)

Figure 4. (a) The 2D and 3D AFM pattern of raffia palm fibers; (b) The 2D and 3D AFM pattern of raffia palm fibers ash particles. 


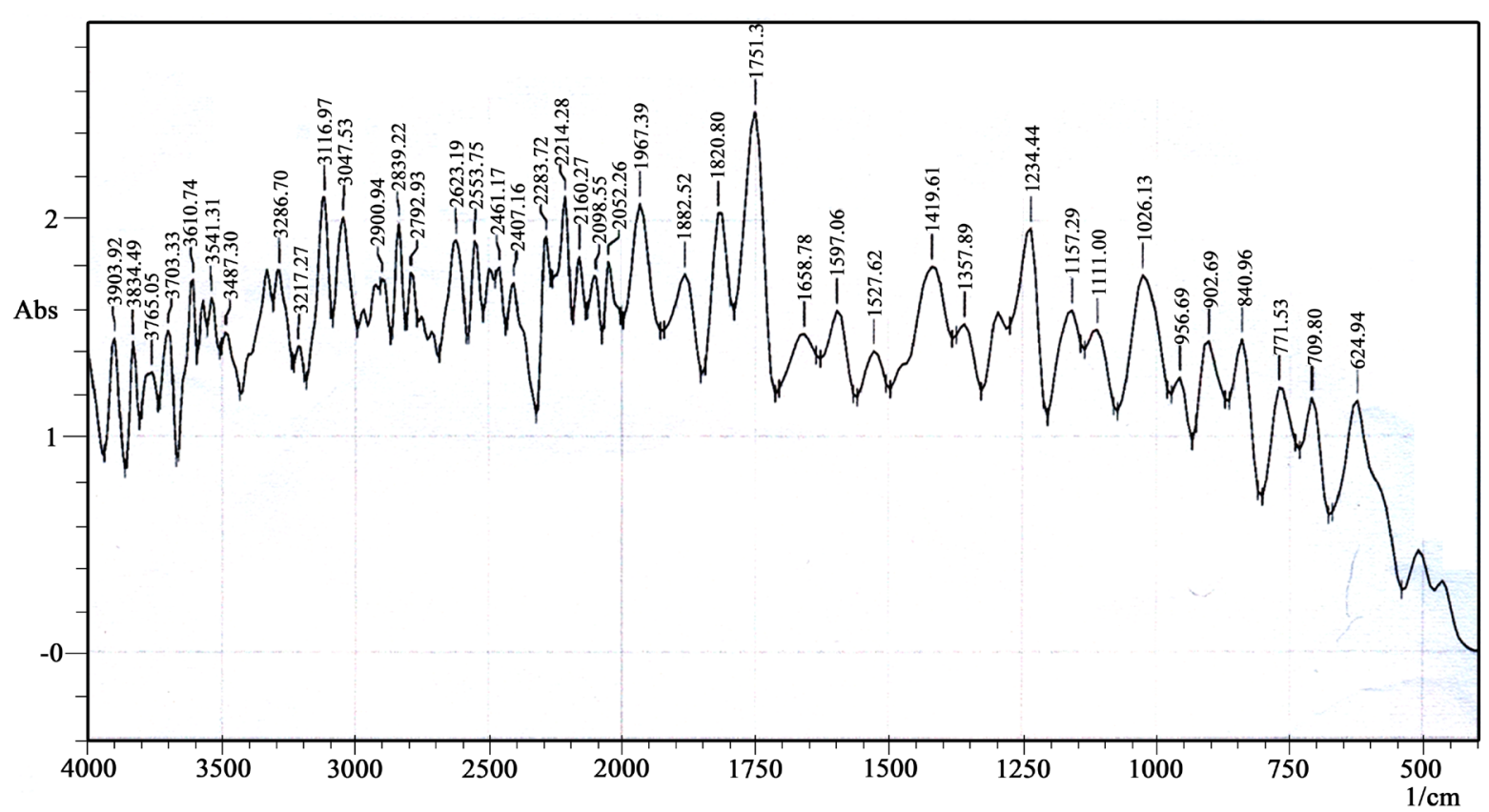

(a)

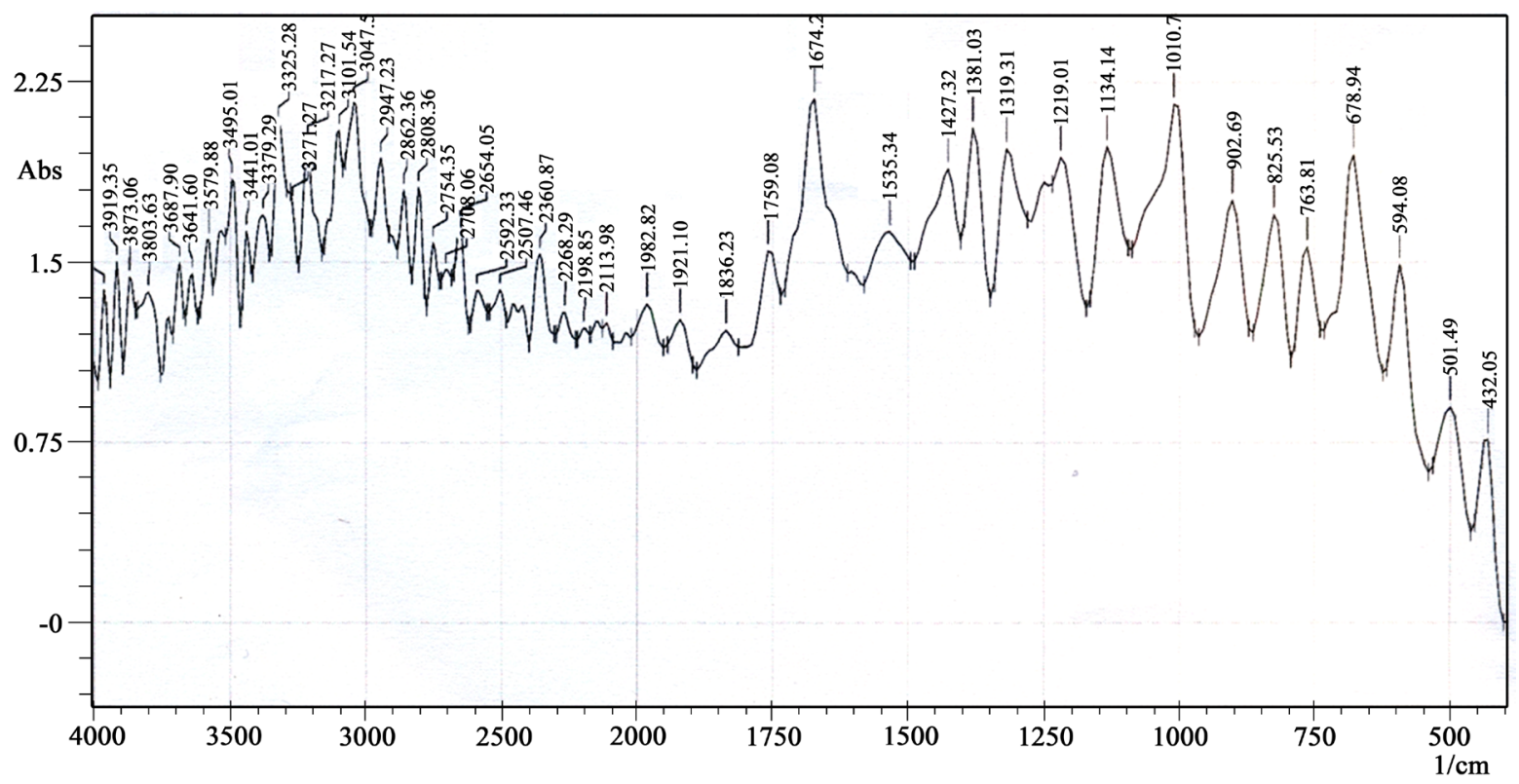

(b)

\section{Figure 5. (a) FT-IR spectroscopy of RPF; (b) FT-IR spectroscopy of RPFAp.}

ing to $\mathrm{CH}_{2}$ deformation vibration of cellulose. Moreover, the peak at $13,656 \mathrm{~cm}^{-1}$ is referring to $\mathrm{C}-\mathrm{H}$ group deformation in cellulose and hemicellulose. A peak found at $1280.73 \mathrm{~cm}^{-1}$ is assigned as $\mathrm{C}-\mathrm{O}$ groups from acetyl group in lignin. Another broad peak detected at $1049.28-1195.87 \mathrm{~cm}^{-1}$ is $\mathrm{C}-\mathrm{H}$ group vibration in cellulose. The peaks in the $324.04-87.54 \mathrm{~cm}^{-1}$ range related to $\mathrm{C}-\mathrm{H}$ vibration of lignin. The stretching of carbonyl group which disappeared in RPFAp may be due to the removal of side chain of acetyl group of acetylated xylan by carbonization at elevated temperature.

The absence of absorption band between $1350 \mathrm{~cm}^{-1}$ to $1600 \mathrm{~cm}^{-1}$ in the RPFAp may further confirm the complete removal of lignin during carbonization process. The FTIR spectrum of the RPF and RPFAp shows a change of peaks from $1689.64 \mathrm{~cm}^{-1}$ to $1651.97 \mathrm{~cm}^{-1}$, which indicates the reduction of carboxyl groups in the 
RPFAp structures. The change of peaks from $1782.23 \mathrm{~cm}^{-1}$ to $1743.65 \mathrm{~cm}^{-1}$ confirms that in the RPFAp, the absorption band of $\mathrm{C}=\mathrm{O}$ group are more due to carbonization. This can also be observed in the reduction of $\mathrm{OH}$ groups from $3047.53 \mathrm{~cm}^{-1}$ to $2954.95 \mathrm{~cm}^{-1}$.

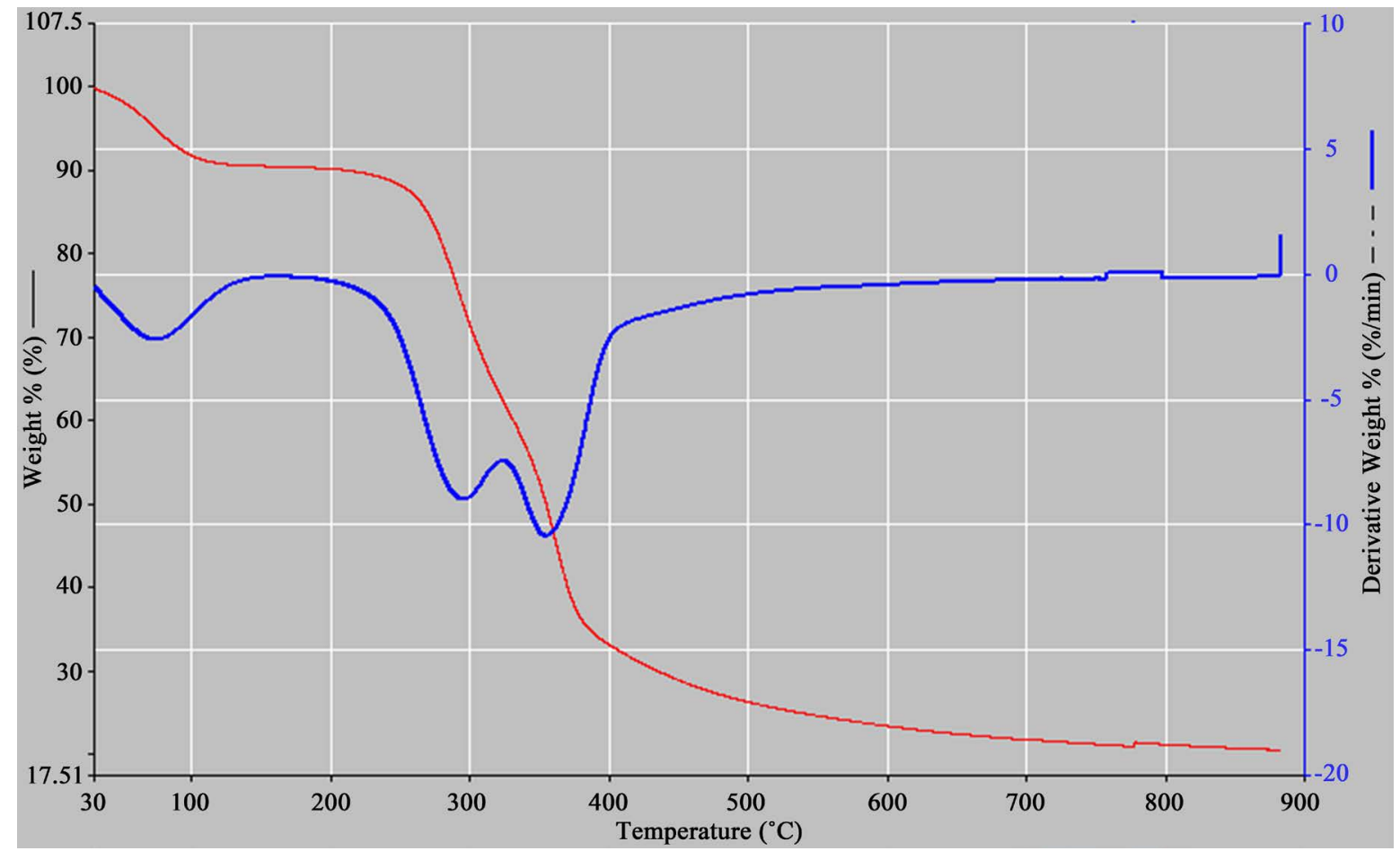

(a)

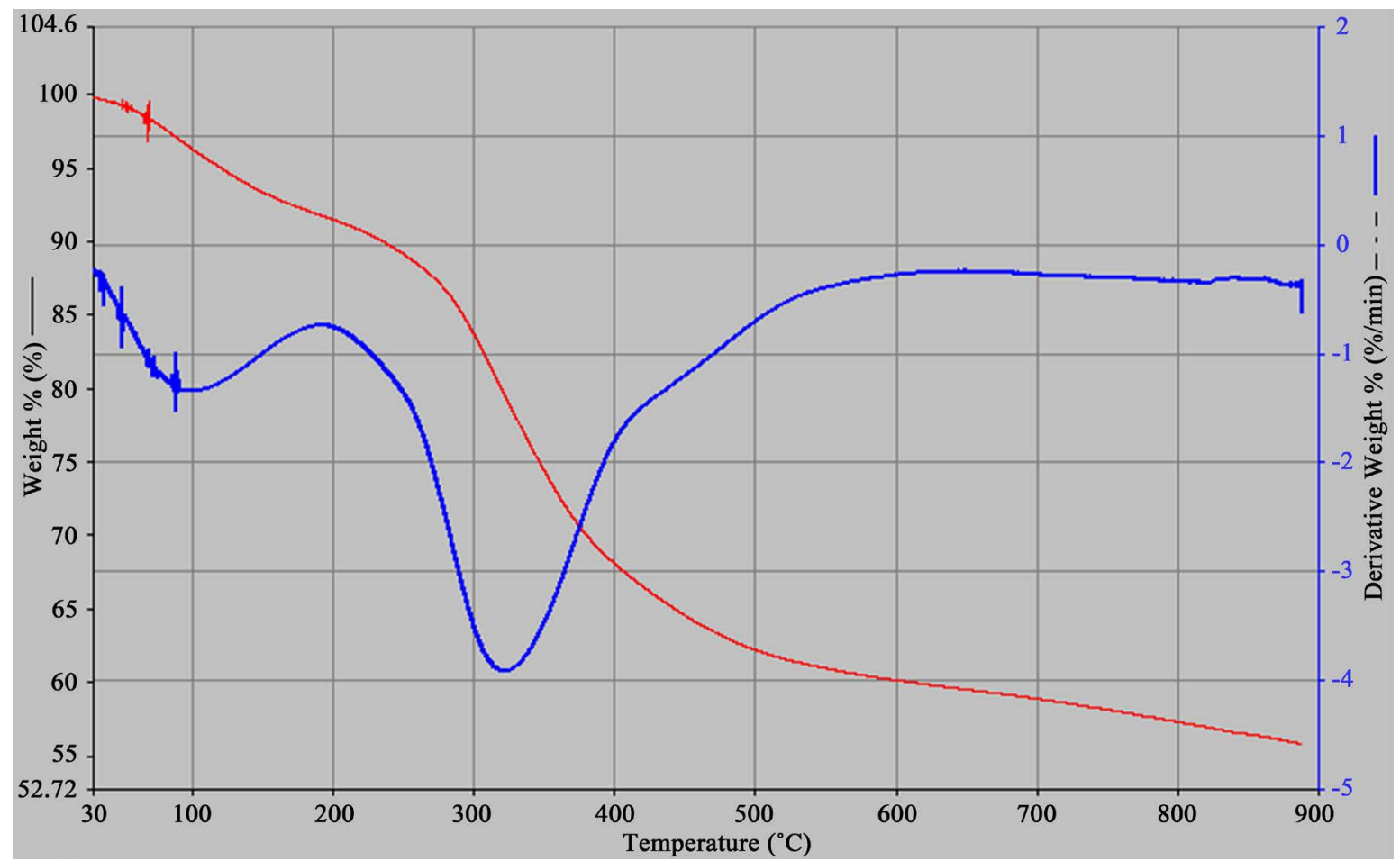

(b)

Figure 6. TGA/DTA of (a) RPF; (b) RPFAp. 
The TGA/DTA curves of the RPF and RPFAp are shown in Figure 6. The temperature at the maximum rate of weight loss $\left(\mathrm{T}_{\mathrm{dmax}}\right)$ is 234.5 (see Figure 6(a)) and $600.56^{\circ} \mathrm{C}$ (see Figure 6(b)) for RPF and RPFAp respectively. The $\mathrm{T}_{\mathrm{dmax}}$ of the Raffia palm fibers increased after carbonization. This indicates that the improvement of the thermal stability occurred due to char formation. The char became like a protective barrier that prevented the thermal decomposition of the Raffia palm fibres. This will form a better char formation, thus leading to a higher thermal resistance.

It can be seen from the DTA curve that the total burning/degradation of the residual particle took place in the above temperature interval. The vaporization of water took place at the first endothermic peak, the burning of cellulose and volatile matter took place between the first endothermic peak and the last endothermic peak, while at the last peak, the maximum thermal decomposition occurred. Thus, the endothermic effects on the Raffia palm fibers are seen in three progressions: dehydrogenation, evaporation of some cellulosic materials and the thermal decomposition of the material. The overall effect is seen in the decreased mass of the sample.

On the other hand, the heat flows which are shown as DSC curves of Figure 7 predict that the huge rates of mass losses in the TGA/DTA curve for RPF could not contribute to the exothermic performance of this sample at expected level. This is because the most of the mass losses are formed from the elimination of the volatiles such as carbon dioxide which play no important role on the calorific output. The exothermic regions for all the

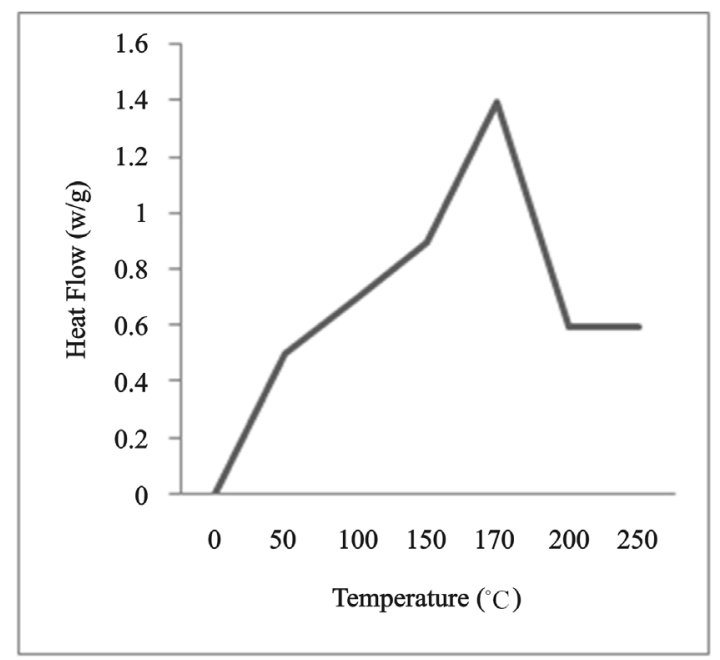

(a)

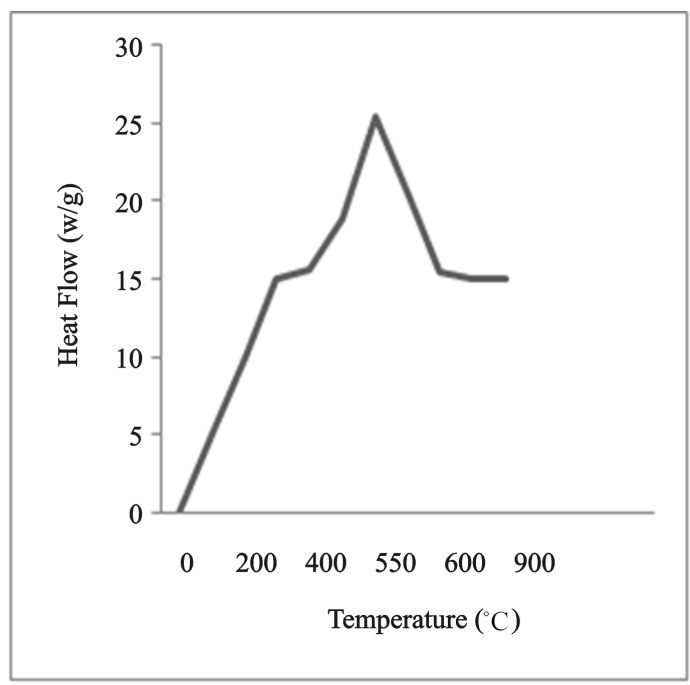

(b)

Figure 7. DSC scan of (a) RPF; (b) RPFAp. 
samples either comprised of two different parts or a unique broad peak having a shoulder, representing the effects of both homogeneous combustion of volatiles and char burning. Also the maximum peaks occurred around $200^{\circ} \mathrm{C}$ (heat flow $1.4 \mathrm{w} / \mathrm{g}$ ) and $550^{\circ} \mathrm{C}$ (heat flow $25 \mathrm{w} / \mathrm{g}$ ) for RPF and RPFAp respectively. The DSC scan can also support that carbonization also improved the thermal stability of the Raffia palm fibers.

\section{Conclusion}

The Raffia palm fibers were characterized by XRD, SEM/EDS, AFM and DSC. Their thermal degradation behaviour was fully investigated through TGA/DTA and DSC curves. The various results obtained are equivalent to that of other agro-waste materials generally used in the production of mortar roofing sheets. This work therefore has confirmed that Raffia palm fibers are potential materials for mortar roofing sheets composites production.

\section{References}

[1] Berhane, Z. (1999) Performance of Natural Fibre Reinforced Mortar Roofing Tiles. Materials and Structures, 27, $347-$ 352. http://dx.doi.org/10.1007/BF02473427

[2] Toledo Filho, R.D. (1999) Brazilian J. of Agricultural and Envir. Eng., 3, 245-256.

[3] Chen, B. and Liu, J.Y. (2007) Mechanical Properties of Polymer-Modified Concretes Containing Expanded Polystyrene Beads. Construction and Building Materials, 21, 7-11. http://dx.doi.org/10.1016/j.conbuildmat.2005.08.001

[4] Eze-Uzomaka, O.J. and Nwadiuto, O.O. (1990) Afri. J. of Sci. and Tech., 8, 6-15.

[5] Fageiri, O.M.E. (1983) Symp. on Appro Building Mater for Low Cost Hous., E. \& F.N. Spon Ltd., New York, 167-176.

[6] Saxena, M., Morchhale, R.K., Asokan, P. and Prasad, B.K. (2002) J of Com. Mater., 42, 367-384.

[7] Toledo Filho, R.D. (2000) Durability of Alkali-Sensitive Sisal and Coconut Fibres in Cement Mortar Composites. Cement and Concrete Composites, 22, 127-143. http://dx.doi.org/10.1016/S0958-9465(99)00039-6

[8] Ramakrishna, G. and Sundararajan, T. (2005) Impact Strength of a Few Natural Fibre Reinforced Cement Mortar Slabs: A Comparative Study. Cement and Concrete Composites, 27, 547-553. http://dx.doi.org/10.1016/j.cemconcomp.2004.09.006

[9] Odera, R.S., 1Onukwuli, O.D. and Osoka, E.C.J. (2013) Emerging Trends in Eng. and Applied Sci (JETEAS), 2, 231234.

[10] Akpabio, U.D., Akpakpan, A.E., Udo, U.E. and Essien, U.C. (2012) Ad in Applied Sci Research, 38, 38-43.

[11] Kandachar, P. and Brouwer, R. (2002) Mater Res Soc Symp Proc., 702, 101-112. 